\title{
Pre-exposure to anti-TNF $\alpha$ decreases COVID-19 symptoms: a multicentre retrospective cohort study
}

\author{
Natalia SOLDEVILA-DOMENECH ${ }^{1}$, Laura $\mathrm{TIO}^{2}$, Jone LLORENTE-ONAINDIA ${ }^{2}$, Elena \\ MARTÍN-GARCÍA ${ }^{3}$, Pau NEBOT ${ }^{1}$, Rafael de la Torre ${ }^{2}$, Alba GURT ${ }^{4}$, Rafael \\ Maldonado $^{3}$, and Jordi MONFORT ${ }^{5}$ \\ ${ }^{1}$ Institut Hospital del Mar d'Investigacions Mèdiques \\ ${ }^{2}$ Institut Hospital del Mar d'Investigacions Mediques \\ ${ }^{3}$ Pompeu Fabra University Department of Experimental and Health Sciences \\ ${ }^{4}$ Parc Sanitari Pere Virgili \\ ${ }^{5}$ Hospital del Mar
}

June 8, 2020

\begin{abstract}
AIM: Immune response hyperactivation is critical in the progression of coronavirus disease (COVID-19). We studied the effect of the pre-exposure to disease-modifying antirheumatic drugs (DMARDs) that decrease immunological responses on the incidence of COVID-19 symptoms to explore therapeutic approaches in its early stages. METHODS: Multicentre retrospective cohort study including 2,494 patients with inflammatory diseases recruited from 14 primary care centres in Barcelona (Spain). The primary outcome was the presence of confirmed or highly suspected COVID-19 (hsCOVID-19) symptoms reported during March 2020 at primary care or hospital emergency department. Multivariable Poisson regression models were fitted to estimate hsCOVID-19 symptoms relative risk (RR) adjusted by comorbidities. RESULTS: Biological $(\mathrm{RR}=0.46, \mathrm{CI} 95 \%=0.31-0.67)$ and synthetic $(\mathrm{RR}=0.62$, CI95\%=0.43-0.91) DMARDs used in immunomediated inflammatory diseases diminished the incidence of symptomatic cases of hsCOVID-19. Striking sex differences were revealed. Protective effects of anti-TNF $\alpha$ pre-exposure $(\mathrm{RR}=0.50, \mathrm{CI} 95 \%=0.33-0.75)$ were higher in women $(\mathrm{RR}=0.33, \mathrm{CI} 95 \%=0.17-0.647)$, whereas anti-IL6/12/17/23 compounds pre-exposure $(\mathrm{RR}=0.47$, CI95\% $=0.24-0.92)$ produced slightly higher protective effects in men $(\mathrm{RR}=0.44, \mathrm{CI} 95 \%=0.15-1.68)$. Pre-exposure to low glucocorticoid doses also revealed sex differences decreasing the incidence of hsCOVID-19 symptoms predominantly in women $(\mathrm{RR}=0.72$, CI95\%=0.42-1.22). A merely protective effect of pre-exposure to chloroquine/hydroxychloroquine (RR 0.76, CI95\%=0.36-1.62) was observed. CONCLUSION: We identified specific DMARDs with different immune-depressor mechanisms that decrease hsCOVID-19 symptoms with striking sex differences. These results underline the potential interest of starting clinical trials with anti- $\mathrm{TNF} \alpha$ compounds in women to evaluate their efficacy in minimizing disease progression in the early stages of COVID-19.
\end{abstract}

\section{INTRODUCTION}

Since December 2019, cases of severe acute respiratory syndrome coronavirus 2 (SARS-CoV-2) infection leading to a novel disease called COVID-19 were initially identified in China. SARS-CoV-2 infection causes respiratory symptoms that range from mild forms of presentation to more serious ones that can risk patients' lives, causing pneumonia, and damage to other organs, particularly the immune and blood system [1-3]. This disease has rapidly expanded to multiple countries leading to a pandemic situation in March 2020 now affecting 5.595.091 individuals worldwide, with a global mortality of 350.547 deaths on May 27th. Today, the situation is dramatic in some European countries, such as Spain with 236.259 cases and 27.117 deaths, being the $2^{\text {nd }}$ country in the world with higher COVID-19 mortality per capita, following Belgium [4]. This 
official mortality numbers only reflect the casualties occurring in the hospitals, not in nursing homes or at home, and considering the low availability of accurate COVID-19 diagnostic tests, the current situation in Spain could unfortunately be worse. Furthermore, some patients are asymptomatic $[5,6]$ and the current prevalence reflects a possible underdiagnosis of the infection that has facilitated the disease expansion. This, together with the massive social and political activities that were promoted in Spain in early March in spite of the well-known previous recommendations of the WHO could influence this rapid progression.

Severe cases of the disease represent about $15 \%$ of COVID-19 patients [7] and require their hospitalization. Given the progressive spread of the pandemic in relation to the available health resources, it is essential to find new equally effective treatments, especially when evidence indicates that a rapid shortage of some of the existing treatments' stock may occur. Therefore, there is an urgent need to find novel treatments in the early stages of COVID-19 to prevent the progression to severe forms of the disease. Evidence suggests that the hyperactivation of the immune response is of paramount relevance in COVID-19 progression. The accumulated knowledge about the pathophysiology of this disease reveals a crucial involvement of different molecules of the main inflammatory pathways, including interleukins 1,6 and 8 (IL-1, IL-6, IL-8) and tumour necrosis factor alpha $(\mathrm{TNF} \alpha)$. Currently, drugs inhibiting some of these pathways are used in the routine management of COVID-19, although results from clinical trials are still required to corroborate their effectiveness [8]. Clear examples are anti-IL-6 compounds for patients with severe forms of COVID-19 [9-11] and hydroxychloroquine, widely used and highly questioned that has been now withdrawn from the clinical trials due to the serious adverse effects [12-13].

Immunomodulated inflammatory diseases (IMIDs) are a group of unrelated and highly diverse conditions, such as rheumatoid arthritis and psoriasis, that share a common pathogenesis pathway, i.e., an immune dysregulation leading to an imbalance in inflammatory cytokines. Treatments to relieve IMIDs symptoms share similar mechanisms of action and are namely disease modifying antirheumatic drugs (DMARDs), subdivided into two main subgroups: synthetic and biological. Biological DMARDs (bDMARDs) are monoclonal antibodies that have a much higher affinity and selectivity for the targeted protein than synthetic DMARDs (sDMARDs). Patients with an autoimmune disease might be at higher risk of developing severe infections, as these medications are immunosuppressants [14]. In that context, the Rheumatology, Dermatology and Gastroenterology services of Hospital del Mar began to follow-up more closely on their patients and, surprisingly, they reported less COVID-19 symptoms than expected. Considering the role of the immune system in COVID-19 progression and that these immunomodulatory treatments are not associated with worse COVID19 outcomes [15] we hypothesize that specific compounds used in IMIDs treatment could provide therapeutic benefits in early stages of COVID-19.

\section{METHODS}

\section{Study design and population}

This is a multicentre retrospective cohort study aimed (I) to evaluate the effect of different disease modifying anti-rheumatic drugs (DMARDs) on the accumulated incidence of COVID-19 symptoms during March 2020 in patients with IMIDs living in Barcelona (Spain); and (II) to explore the possibility of new treatments in early stages of COVID-19. Patients with suspected IMIDs (first visits or confirmed diagnostic in successive visits), who had been referred from 14 Primary Care Centres to the outpatient Rheumatology, Dermatology and Gastroenterology services of Hospital del Mar (referral hospital from Barcelona) from September 2019 to March 2020 were recruited. The exclusion criteria were $<18$ years old, previous death not related with SARS-CoV-2 infection and patients tested negative for SARS-CoV-2 or without follow up at the primary care centre during the studied period. The study was undertaken according to Good Clinical Practice guidelines and the Declaration of Helsinki. The research ethics review committee of Parc de Salut Mar approved the protocol (2020/9246).

\section{Data collection}

A clinical history revision of the included patients was performed, focusing mainly at patients' consulting disease, comorbidities and the treatments being currently followed by them (Supplementary Table 1 and 
Supplementary Table 2 ). Briefly, diabetes, pulmonary disease, cardiovascular (CV) disease and chronic kidney disease were registered if they were present in the clinical history. In the case of arterial hypertension (AHT) and transplantation, they were only recorded if patients were receiving treatment with specific drugs for those comorbidities. Finally, cancer was recorded only if the patient had an active process or was following a treatment for a previous cancer, during the studied period.

The primary outcome was the presence of confirmed or highly suspected symptomatology of COVID-19 (hsCOVID-19) informed both at the hospital or at the primary care centre, from the $1^{\text {st }}$ to the $29^{\text {th }}$ of March 2020. Following the Spanish health authorities' recommendation for the identification in primary care centres of patients with unconfirmed symptoms of SARS-CoV-2 infection, it was considered that patients presented symptoms when they reported fever (defined as axillary temperature $>37^{\circ} \mathrm{C}$ ) and shortness of breath and/or cough. If only fever was present, it was only considered as symptoms if it came with at least two of the following symptoms: anosmia, ageusia, rhinorrhea, diarrhea of one week of evolution, pharyngitis, odynophagia or arthromyalgia.

\section{Statistical analysis}

Sample size calculations were based on the assumed rate of patients in the group of individuals unexposed to DMARDs (0.15). With 5\% significance level and $80 \%$ power, 1,701 subjects in the exposed group and 850 in the unexposed group were needed to detect a minimum relative risk (RR) of 1.3.

To evaluate the associations between different treatments and the presence of hsCOVID-19 symptoms, Poisson regression models with robust variance estimation were used to estimate $\mathrm{RR}$ and $95 \%$ confidence intervals $(95 \%$ CI $)$ [4]. Models were adjusted by sex, age, diabetes, pulmonary disease, cardiovascular disease, chronic kidney disease, and active cancer or treatment. Model 1 aimed to estimate the association between treatments grouped by drug type (1) bDMARDs; (2) sDMARDs, (3) glucocorticoids, (4) chronic nonsteroidal anti-inflammatory drugs (NSAIDs) and (5) Anti-hypertensive drugs. Then, associations between hsCOVID19 symptoms were estimated by each individual treatment (with $>100$ exposed patients; reference category $=$ "unexposed"; Model 2). Finally, as anti-TNF $\alpha$ treatments were the major group of bDMARDs, the effect of each anti-TNF $\alpha$ drug was estimated separately in model 3. Model 3 also included the effect of anti-IL17 and anti-IL23(-12), but anti-IL6 could not be analysed as a separate group as there were not hsCOVID-19 symptoms reported among individuals exposed to IL- 6 antagonists. Interactions between different drug types were also tested (model 4). Models 1 and 2 were furthermore replicated in the subgroup of individuals aged [?] 60 years (model 5 and 6 ) and $>60$ years (model 7 and 8). All analyses were stratified by sex. Finally, the main treatment indications, together with the studied comorbidities (sex, age, cardiovascular disease, diabetes, pulmonary disease, kidney disease and cancer) were used to create a matched dataset for the exposure to each treatment Propensity score matching was applied for the exposure to anti-TNF $\alpha$, anti-proinflammatory ILs, glucocorticoids ([?]10 mg/day in women) and chloroquine/hydroxychloroquine. Statistical analyses were performed using R (R Foundation for Statistical Computing, Vienna, Austria) version 3.5.2.

\section{RESULTS}

A total of 2,544 individuals were examined for eligibility and 2,494 fulfilled inclusion/exclusion criteria and were finally included in the analysis, $902(36.2 \%)$ men and 1,592 (63.8\%) women. Table 1 shows the description of the studied population. The mean age (SD) was 58.7 (15.7) and the most prevalent underlying pathologies were spondyloarthritis $(32.6 \%)$, rheumatoid arthritis $(21.6 \%)$ and osteoarthritis $(25.1 \%)$. Almost half of individuals had at least one of the following comorbidities: hypertension (34\%), diabetes (11.5\%), pulmonary disease (14\%), cardiovascular disease (11\%), chronic kidney disease (5\%), active cancer or treatment $(3 \%)$ and post-transplant $(0.3 \%)$. In terms of treatments, $45 \%$ of individuals were taking biologic DMARDs (59\% in men and $36 \%$ in women), primarily anti-TNF $\alpha$ ( $30 \%$ in total; $42 \%$ in men and $24 \%$ in women) and anti-IL6/12/17/23 compounds (11\%, $2 \%$ of which corresponded to anti-IL6, $3 \%$ to anti-IL17 and $6 \%$ to antiIL12/23). A third of the population were exposed to synthetic DMARDs, being methotrexate, leflunomide and chloroquine/hydroxychloroquine the most prevalent ones (22\%, $5 \%$ and $5 \%$, respectively). Glucocorticoid consumption in women was twice that in men (26\% vs $13 \%)$ but, in both cases, doses of glucocorticoids 
higher than $10 \mathrm{mg}$ /day were unusual $(<4 \%)$. NSAIDs and anti-hypertensive drugs were taken by the $20 \%$ and $27 \%$ of individuals, respectively. A $15.8 \%$ of the population $(18.4 \%$ in women and $11.2 \%$ in men) did not take any of the registered treatments (Supplementary Table 3 ).

The incidence of confirmed or hsCOVID-19 symptoms during March 2020 was 6.3\% ( $\mathrm{N}=156)$, being slightly higher in women than in men (6.8\% vs. $5.3 \%$, respectively). Among them, a $22 \%$ were confirmed cases of COVID-19 and the remaining $78 \%$ had not been tested for SARS-CoV-2. There were 26 individuals ( 8 men and 18 women) hospitalized and there were 4 deaths due to COVID-19.

As shown in Table 2, those presenting hsCOVID-19 symptoms had less spondylarthritis, rheumatoid arthritis or dermatological diseases, and higher osteoarthritis. The proportion of diabetics in the group of individuals with hsCOVID-19 symptoms was $20.5 \%$, while in the group without symptoms was $11.5 \%$. In the case of pulmonary disease, these percentages were $22.4 \%$ and $14.1 \%$, respectively. The proportion of both bDMARDs and sDMARDs was also lower in the group with hsCOVID-19 symptoms.

Adjusted associations between different exposure variables (clinical characteristics and treatments) and hsCOVID-19 symptoms are shown inTable 3 . Diabetes and pulmonary disease were associated with an increased RR of hsCOVID-19 symptoms, with overall $\mathrm{RR}_{\mathrm{m} 1}$ of $1.64(95 \% \mathrm{CI} 1.09,2.47)$ and 1.47 (95\% CI 1.02, 2.13). Regarding treatments, all bDMARDs presented a RR of 0.46 (95\% CI $0.31,0.67)$ and all sDMARDs presented a RR of $0.62(95 \%$ CI $0.43,0.91)$. Specifically, TNF- $\alpha$ antagonists presented RR of $0.50(95 \% \mathrm{CI}$ $0.33,0.75)$ in the whole population. This protective effect was even higher in women $(\mathrm{RR}=0.33 ; 95 \% \mathrm{CI} 0.17$, $0.64)$, while in men the effect size of the association was smaller and not statistically significant $(\mathrm{RR}=0.76$; $95 \%$ CI $0.41,1.43$ ). All types of TNF- $\alpha$ antagonists (adalimumab, certolizumab, etanercept, golimumab and infliximab) showed $\mathrm{RR}$ estimates $<1$, although were only statistically significant for adalimumab $(\mathrm{RR}=0.53$, CI95\% 0.31, 0.93) and etanercept $(\mathrm{RR}=0.37$, CI95\% 0.16, 0.88). The RR of anti-IL6/12/17/23 compounds were $0.47(95 \%$ CI $0.24,0.92)$; with potentially higher effects of anti-IL17 (RR=0.20; CI95\% 0.03-1.38) than anti-IL23(12) $(\mathrm{RR}=0.80 ; \mathrm{CI} 95 \%$ 0.39, 1.65). Methotrexate and chloroquine/hydroxychloroquine presented an RR of $0.71(95 \% \mathrm{CI} 0.46,1.08)$ and 0.76 (95\% CI $0.36,1.62)$, respectively. The RR of leflunomide was $0.66(95 \% \mathrm{CI} 0.28,1.58)$ in the whole population, with higher risk reduction in men $(\mathrm{RR}=0.36 ; 95 \% \mathrm{CI}$ $0.07,1.75)$ than in women $(\mathrm{RR}=0.81 ; 95 \% \mathrm{CI} 0.29,2.87)$. Glucocorticoids at doses of [?] $10 \mathrm{mg} /$ day also showed a risk reduction of about $30 \%$ in women $\left(\mathrm{RR}_{\mathrm{m} 1}=0.72,95 \% \mathrm{CI} 0.42,1.22\right)$. Figure 1 represents the adjusted RR for presenting hsCOVID-19 symptoms according to the exposure to different treatments in men and women. The interactions between most prevalent combinations of treatments were included in Model 4(Supplementary Table 4 ) and were not statistically significant, except for the interaction between biologic and synthetic DMARDs $(\mathrm{RR}=4.3$; CI95\% 2.00, 9.25).

A sub-analysis in individuals aged 60 or older $(\mathrm{N}=1228)$, compared to individuals under $60(\mathrm{~N}=1266)$ was performed (Supplementary Table 5 ). The association between anti-TNF- $\alpha$ and hsCOVID-19 symptoms was maintained in both groups $\left(\mathrm{RR}_{<60}=0.55\right.$; CI95\% 0.33, 0.91 vs $\mathrm{RR}=0.43$; CI95\% 0.20, 0.92). In the case of anti-IL6/12/17/23 compounds their effect was statistically significant in individuals under 60 years $\left(\mathrm{RR}_{<60}=0.36\right.$; CI95\% 0.15, 0.85). The effect of all biologic DMARDs was the same in both age groups, but this was not in the case of synthetic DMARDs, with $\mathrm{RR}<60=0.77$ (CI95\% 0.46, 1.29) and RR[?]60 = 0.48 (CI95\% 0.27, 0.86). The effect of glucocorticoids ([?] $10 \mathrm{mg} /$ day) was higher in younger women $(\mathrm{RR}<60=$ 0.50 ; CI95\% 0.20, 1.24) than older women $(\mathrm{RR}=0.91$; CI95\% 0.46, 1.79).

Finally, the adjusted RR estimates using propensity score matching for the exposure to each treatment are shown in Supplementary Table 6 . The RR of anti-TNF $\alpha$ was almost equivalent to the observed in the unmatched database ( $\mathrm{RR}=0.65$; CI95\% 0.37-1.16) while for anti-IL6/12/17/23 compounds, glucocorticoids and chloroquine/hydroxychloroquine, the associations presented greater differences.

\section{DISCUSSION}

Our retrospective cohort study reveals that, during the firsts weeks of the SARS-CoV-2 outbreak in Spain (March 2020), individuals with IMIDs exposed to biologic and synthetic DMARDs presented a lower risk of hsCOVID-19 symptoms than individuals with IMIDs unexposed to these treatments. Previous preliminary 
observations also support our findings [15-17]. These results underline the interest of starting clinical trials with compounds that decrease immunological responses to evaluate their possible efficacy in minimizing the progression of the disease.

The three families of monoclonal antibodies approved to treat rheumatoid arthritis are directed against IL-6, B lymphocyte surface protein CD20 and TNF $\alpha$, three targets of potential protective compounds for hsCOVID-19 symptoms. TNF $\alpha$, IL-6 and B lymphocytes have been reported to play a crucial role in the inflammatory cascade taking place days before the manifestation of the most severe forms of SARS-CoV-2 infection [10], and in the physiopathological processes leading to rheumatoid arthritis [18]. In the present study, TNF- $\alpha$ antagonists were the most abundant biologic DMARDs and showed a $50 \%$ reduction in the relative risk of hsCOVID-19 symptoms. Nevertheless, our cohort included a limited number of patients treated with two important groups of immunomodulatory compounds, IL-6 (52 patients) and B lymphocyte antagonists (42 patients). Interestingly, none of these 94 patients showed hsCOVID-19 symptoms, which agrees with the reported efficacy of the IL-6 antagonists tocilizumab [19] and sarilumab (unpublished observations) in COVID-19 treatment, and with the protective effect of IL-6 antagonists shown in a cross-sectional recent study [17].

Regarding synthetic DMARDs, although their global effect was protective ( $\mathrm{RR}=0.62 ; 95 \% \mathrm{CI} 0.43,0.91)$, our results point that not all synthetic DMARDs would play a protective role against the appearance of hsCOVID-19 symptoms. On the one hand, methotrexate was the most abundant synthetic DMARD and presented a 30\% reduction in the RR of hsCOVID-19 symptoms. Among individuals exposed to leflunomide $(\mathrm{N}=111)$ only 5 presented hsCOVID-19 symptoms. Interestingly, leflunomide produces a stronger and widespread decrease in pro-inflammatory ILs than classical DMDARDs, such as methotrexate with limited effects in ILs expression [20]. On the other hand, the exposure to chloroquine/hydroxychloroquine was not associated with a statistically significant protective effect of hsCOVID-19 symptoms ( $R R=0.76$; CI95\% 0.36, 1.62). These compounds have been widely used to treat COVID-19, although their benefit/risk was questioned due to the side-effects and moderate efficacy in disease progression, in agreement with our results. Accordingly, clinical trials have been now withdrawn due to the recently reported decreased in-hospital survival associated with increased risk of ventricular arrhythmia during hospitalization [12-13].

The severity of COVID-19 symptoms shows clear sex differences with more severe cases and higher mortality reported in men than women [9]. Similar sex differences were revealed in the outcome of influenza A virus infections probably mediated by the impact of sex steroid hormones in immune responses [21]. Although the studied population was not sex-balanced (1592 women vs 902 men) our analyses stratified by sex also revealed potential sex differences in the effects of several immunomodulatory compounds. Indeed, anti-TNF $\alpha$ compounds show higher protective effects in women $(\mathrm{RR}=0.33,95 \% \mathrm{CI} 0.17,0.64)$ than in men $(\mathrm{RR}=0.76$, $95 \%$ CI $0.41,1.43)$. Although a possible sex influence in the therapeutic effects of anti-TNF $\alpha$ compounds is controversial, a better prognosis of ulcerative colitis has been reported in women treated with infliximab, an anti-TNF $\alpha$ monoclonal antibody [22]. Sex differences were also revealed in our study in glucocorticoid effects. Taken into account the high variability of the doses of glucocorticoids used in these patients [23] and the differential effects depending on dose exposure [24], we have stratified glucocorticoid treatment in low ([?]10 $\mathrm{mg}$ of prednisone or equivalent) and high doses (>10 mg). Women exposed to low glucocorticoids doses had a reduced $\mathrm{RR}$ of hsCOVID-19 symptoms $(\mathrm{RR}=0.72$, 95\% CI $0.42,1.22)$, whereas high doses produce the opposite effect $(\mathrm{RR}=1.62,95 \% \mathrm{CI} 0.75,3.52)$. Considering the high availability and safety profile of low doses of glucocorticoids, it would be of interest to evaluate the potential use of such low doses in women as a potential treatment in early periods of SARS-CoV-2 infection to prevent disease progression.

In spite of the potential beneficial effects of biological and synthetic DMARDs, those patients receiving a combination of both groups of compounds $(n=298)$ show enhanced incidence of hsCOVID-19 symptoms $(\mathrm{RR}=4.30$, CI95\% 2.0, 9.3). The strong immunosuppression that should result by the combination of these treatments and the severity of the diseases targeted by these drug combinations may explain this paradoxical effect. Indeed, previous studies have reported that more patients experienced infectious adverse events when increasing doses of synthetic DMARDs were combined with anti-TNF $\alpha$ compounds $[25,26]$. In addition, the 
main reason for combining both treatments is related to the lack of efficacy in these particular patients [27], which could also have influenced our results.

Finally, we made a sub-analysis of patients aged 60 or older taking into account their worse prognosis of the disease [7]. Biological DMARDs showed the same protective effect in both groups of patients $\left(\mathrm{RR}_{<60}=0.47\right.$ and $R_{>60}=0.47$ ), although the subgroup of anti-IL6/12/17/23 ILs showed higher effects in patients under $60(\mathrm{RR}=0.36)$ than in older patients $(\mathrm{RR}=0.77)$. Synthetic DMARDs effects were higher in patients aged 60 or older $(\mathrm{RR}=0.48)$ than in younger individuals $(\mathrm{RR}=0.77)$. In contrast, protective effects of low doses of glucocorticoids were higher in women under $60(\mathrm{RR}=0.50)$ than in older women $(\mathrm{R} R=0.91)$ underlying the potential interest of this treatment in this particular population.

The results obtained here may be interpreted in the light of the following limitations. First, taking into account that the main interest of our study was focused on the early stages of COVID-19 pandemic in Spain, we included patients showing hsCOVID-19 symptoms due to the scarcity of COVID-19 tests that for ethical reasons were only reserved to patients showing more severe disease symptoms. Indeed, large cohorts of patients with mild symptoms and confirmed COVID-19 tests were not available in Spain at these early moments. Therefore, we and others [17] have used a similar research strategy based on patients showing hsCOVID-19 symptoms as the unique possible research approach available to perform this kind of early studies in Spain on the protective effects of medication pre-exposure. It is also important to underline that the symptoms were recorded from 14 days before the COVID-19 alarm was announced in Spain (March 16th) when patients could be supposed to protect themselves more if they are at risk. Therefore, this potential self-protection would not represent any possible bias for the interpretation of our results considering the time schedule of our symptoms recording. Second, the indications for each treatment not only depend on the underlying pathology, but also on the specific clinical manifestations of each patient, and some of the indications are risk factors of COVID-19 [28]. Given the heterogeneity of the studied treatments and underlying pathologies, it is difficult to analyse all the factors that could cause confounding by indication. However, RR estimates of hsCOVID-19 symptoms after propensity score matching with some of the covariates that predict receiving anti-TNF $\alpha$ and other treatments were similar than RR estimates in the unmatched sample (Supplementary Table 6). The slightly different RRs found with these treatments matching the above mention covariates suggest that some of these IMID may represent an increased risk for hsCOVID-19 symptoms. Indeed, these particular comorbidities have been reported to increase COVID-19 susceptibility [29]. Furthermore, patients receiving these immunomodulatory treatments have an enhanced propensity to bacterial infection [29] that could eventually provide manifestations similar to hsCOVID-19 symptoms. In spite of this possible bias that would impair the results obtained with these treatments, we have obtained promising RRs with these compounds that suggest significant protective effects on COVID-19 symptoms.

In summary, our results report that pre-exposure to DMARDs does not enhance the incidence of COVID19 symptoms. In contrast, we identify specific DMARDs with different immune-depressor mechanisms that decrease hsCOVID-19 symptoms incidence with potential sex differences. These results underline the interest of starting clinical trials in women with anti-TNF $\alpha$ compounds in early periods of SARS-CoV-2 infection to evaluate their possible efficacy in minimizing the severity of COVID-19 progression. We have also revealed protective effects of low doses of glucocorticoids in women, which may also open new possibilities for low cost and safe early COVID-19 treatment mainly considering the current progression of the disease in countries with limited health resources. Interestingly, the protective effects of anti- IL6/12/17/23 compounds were mainly revealed in patients younger than 60 , which underlies the need of an appropriate patient stratification for optimizing the results of the future clinical trials. The protective effects reveal with these immunomodulatory compounds may open novel therapeutic strategies to avoid serious COVID-19 manifestations, future deaths and, ultimately, the collapse of the health system.

Acknowledgements: We thank all patients who participated in the study, Gemma Vilagut (PhD) for her guidance and support on the statistical analysis and Mònica Gratacós (PhD) for translating the clinical protocol into English, for English language support and proofreading of the manuscript. The Covidmar Study Group members are: Hospital del Mar, Barcelona: Selene Labrada, Miguel Mejía-Torres (Rheumatology Ser- 
vice) and Irene Carrión-Barberà, Carolina Pérez-García, Fabiola Ojeda, Tarek Carlos Salman-Monte, Josep Blanch-Rubió (Rheumatology Service \& IMIM-Hospital del Mar Medical Research Institute) collected data and provided care for study patients; IMIM-Hospital del Mar Medical Research Institute: Luciano Polino, Laura Triginer, Anna Ribes (Cell Research on Inflammation and Cartillage Research Group, Inflammatory and Cardiovascular Processes Program) collected data; Maria-Victòria Puig (Integrative Pharmacology and Systems Neuroscience Research Group, Neurosciences Research Program \& IMIM-Hospital del Mar Medical Research Institute); contributed to analysis design; Parc Sanitari Pere Virgili, Barcelona: Maria Teresa Martí Vila, Maria Luisa Perez Miras (CAP Vila Olímpica) collected data; Universitat Pompeu Fabra, Barcelona: Beltrán Álvarez-Pérez, Araceli Bergadà-Martínez, Pablo Calvé Alba Calvet-Pavón, Mireia Carcolé, Laura Domingo-Rodríguez, Alejandra Escudero-Lara, Lorena Galera-López, Jolita Jančytė, Marta Linares-López, Sara Martínez-Torres, Antonio Ortega-Álvaro, Andrés Ozaita, Sheila Piedra-Barrull, Dulce Real-Muñoz, Maria Sanchis-Ollé, Clara Seira Oriach, Miquel-Ângel Serra, Anna Vázquez-Oliver (Laboratory of Neuropharmacology, Department of Experimental and Health Sciences \& IMIM-Hospital del Mar Medical Research Institute) collected data.

Competing interests : All authors have completed the ICMJE uniform disclosure form at www.icmje.org/coi_disclosure.pdf, and declare: the submitted work was supported by the Hospital del Mar; outside the submitted work, NSD has received funding from Centro de Información Cerveza y Salud (CICS); AG has received research grants or consulting fees from Astrazeneca and Bioiberica S.A.U., RM has received research grants or consulting fees from Aelis, Almirall, Boehringer Ingelheim, BrainCo, Esteve, Ferrer, GlaxoSmithKline, Grünenthal, GW Pharmaceuticals, Janus, Lundbeck, Pharmaleads, Phytoplant, Rhodes, Sanofi, Spherium, Union de Pharmacologie Scientifique Appliquée, Upjohn, and Uriach; JM has received grants or consulting fees from Procare Health Iberia S.L, Esteve, Labhra, Bioibérica S.A.U, Grunenthal Pharma S.A, Pfizer, OPKO Heath Spain S.L.U and Roche Pharma S.A. LT, JL-O, PN, EM-G and RdlT declare no competing interests.

Funding : "Ministerio de Ciencia, Innovación y Universidades" (\#AEI-SAF2017-84060-R FEDER to RM, \#DPI2016-80283-C2-2-R), "Ministerio de Sanidad, Servicios Sociales e Igualdad" (\#RD16/0017/0020 \& \#PNSD-2017I068 to RM, \#PI18/00059 to TCS-M) and "Generalitat de Catalunya" (\#2017-SGR-669 \& \#ICREA-Acadèmia 2015 to RM, \#2017-SGR-138 to RdlT). NSD is recipient of predoctoral fellowship \#2019-DI-47 from the DIUE-AGAUR of the "Generalitat de Catalunya". There is not a private sponsor for this study.

Ethical approval : The observational study was approved by the Parc de Salut Mar Ethical Committee on Clinical Studies (ref. 2020/9246) before it started, and was monitored by the Clinical Trial Unit of Rheumatology Service at Hospital del Mar. Due to the nature of the study (all the data are completely anonymous), the importance of immediate results, and their implication for the treatment of the SARSCOV-2 pandemic, it is not planned to obtain informed consent from the participants. The Clinical Protocol and the STROBE checklist are attached as Supplementary files (see Supporting Information).

Data availability : Requests to access data should be addressed tojmonfort@parcdesalutmar.cat. Deidentified individual participant data (including data dictionary) will be available to medical researchers by request in accordance with local registration and ethical approval when the article has been published until $30 / 4 / 2030$. All proposals requesting data access will need to specify an analysis plan and will need approval of the scientific board before any data can be released.

The lead author (RM) affirms that the manuscript is an honest, accurate, and transparent account of the study being reported; that no important aspects of the study have been omitted; and that any discrepancies from the study as planned and registered have been explained

\section{REFERENCES}

1. Wang D, Hu B, Hu C, Zhu F, Liu X, Zhang J, et al. Clinical Characteristics of 138 Hospitalized Patients with 2019 Novel Coronavirus-Infected Pneumonia in Wuhan, China. JAMA 2020; 323:1061-1069. 
2. Huang C, Wang Y, Li X, Ren L, Zhao J, Hu Y, et al. Clinical features of patients infected with 2019 novel coronavirus in Wuhan, China. Lancet 2020; 395:497-506.

3. Chen N, Zhou M, Dong X, et al. Epidemiological and clinical characteristics of 99 cases of 2019 novel coronavirus pneumonia in Wuhan, China: a descriptive study. Lancet 2020; 395: 507-513.

4. Dong E, Du H, Gardner L. An interactive web-based dashboard to track COVID-19 in real time. Lancet Infect Dis 2020; 3099:19-20.

5. Mizumoto K, Kagaya K, Zarebski A, Chowell G. (2020). Estimating the asymptomatic proportion of coronavirus disease 2019 (COVID-19) cases on board the Diamond Princess cruise ship, Yokohama, Japan. Eurosurveillance. [Online] Available fromhttps://www.eurosurveillance.org/content/10.2807/1560- 7917.ES.2020.25.10.2000180 [Accessed 18th April 2020].

6. Nishiura H, Kobayashi T, Suzuki A, Jung SM, Hayashi K, Kinoshita R, et al. Estimation of the asymptomatic ratio of novel coronavirus infections (COVID-19). Int J Infect Dis 2020; 94:154-155

7. Wu Z, Mc Googan JM. Characteristics of and Important Lessons from the Coronavirus Disease 2019 (COVID-19) Outbreak in China: Summary of a Report of 72314 Cases from the Chinese Center for Disease Control and Prevention. JAMA 2020; 323:1239-1242.

8. Zhong J, Tang J, Ye C, Dong L (2020) The immunology of COVID-19: is immune modulation an option for treatment? Lancet Rheumatol. DOI:10.1016/S2665-9913(20)30120-X

9. Zhang W, Zhao Y, Zhang F, Wang Q, Li T, Liu Z, et al. The use of anti-inflammatory drugs in the treatment of people with severe coronavirus disease 2019 (COVID-19): The experience of clinical immunologists from China. Clin Immunol 2020; 214:108393.

10. Zhou F, Yu T, Du R, Fan G, Liu Y, Liu Z, et al. Clinical course and risk factors for mortality of adult inpatients with COVID-19 in Wuhan, China: a retrospective cohort study. Lancet 2020; 395:1054-1062. Erratum in: Lancet 2020; 395:1038.

11. Fu B, Xu X, Wei H. Why tocilizumab could be an effective treatment for severe COVID-19? J Transl Med 2020; 18:164.

12. Mehra MR, Desai SS, Ruschitzka F, Patel AN. Articles Hydroxychloroquine or chloroquine with or without a macrolide for treatment of COVID-19: a multinational registry analysis. Lancet 2020; $6736(20): 1-10$.

13. Adhanom Ghebreyesus, T. WHO Director-General's opening remarks at the media briefing on COVID19

14. Memoli MJ, Athota R, Reed S, Czajkowski L, Bristol T, Proudfoot K, et al. (2014). The natural history of influenza infection in the severely immunocompromised vs non immunocompromised hosts. Clin Infect Dis 2014; 8:214-24.

15. Haberman R, Axelrad J, Chen A, Castillo R, Yan D, Izmirly P, et al. Covid-19 in Immune-Mediated Inflammatory Diseases - Case Series from New York. N Engl J Med 2020; DOI:10.1056/NEJMc2009567.

16. Feldmann M, Maini RN, Woody JN, Holgate ST, Winter G, Rowland M, et al. Trials of antitumour necrosis factor therapy for COVID-19 are urgently needed. Lancet 2020; DOI:10.1016/S01406736(20)30858-8.

17. Michelena X, Borrell H, Lopez-Corbeto M, Lopez-Lasanta M, Moreno E, Pascual-Pastor M, et al. Incidence of COVID-19 in a cohort of adult and paediatric patients with rheumatic diseases treated with targeted biologic and synthetic disease-modifying anti-rheumatic drugs. Semin Arthritis Rheum 2020; 50:564-70.

18. Ceribelli A, Motta F, De Santis M, Ansari AA, Ridgway WM, Gershwin ME, et al. Recommendations for coronavirus infection in rheumatic diseases treated with biologic therapy. J Autoimmun 2020; 109:102442.

19. Xu X, Han M, Li T, Sun W, Wang D, Fu B, et al. Effective treatment of severe COVID-19 patients with tocilizumab. Proc Natl Acad Sci. DOI:10.1073/pnas.20056151171.

20. Kraan MC, Smeets TJ, van Loon MJ, Breedveld FC, Dijkmans BA, Tak PP. Differential effects of leflunomide and methotrexate on cytokine production in rheumatoid arthritis. Ann Rheum Dis 2004; 63:1056-1061. 
21. Vom Steeg LG, Klein SL. Sex and sex steroids impact influenza pathogenesis across the life course. Semin Immunopathol 2019; 41:189-194.

22. Nasuno M, Miyakawa M, Tanaka H, Motoya S. Short-and Long-Term Outcomes of Infliximab Treatment for Steroid-Refractory Ulcerative Colitis and Related Prognostic Factors: A Single-Center Retrospective Study. Digestion 2017; 95:67-71.

23. Ruiz-Irastorza G, Danza A, Khamashta M. Glucocorticoid use and abuse in SLE. Rheumatol 2012; $51: 1145-53$.

24. Meng J, Xiao G, Zhang J, He X, Ou M, Bi J, et al. Renin-angiotensin system inhibitors improve the clinical outcomes of COVID-19 patients with hypertension. Emerg Microbes Infect 2020; 9:757-60.

25. Burmester GR, Kivitz AJ, Kupper H, Arulmani U, Florentinus S, Goss SL, et al. Efficacy and safety of ascending methotrexate dose in combination with adalimumab: The randomised CONCERTO trial. Ann Rheum Dis 2015; 74:1037-44.

26. Honkila M, Niinimaki R, Taskinen M, Kuismin O, Kettunen K, Saarela J, et al. A nearly fatal primary Epstein-Barr virus infection associated with low NK-cell counts in a patient receiving azathioprine: a case report and review of literature. BMC Infect Dis 2019; 19:404.

27. Van Vollenhoven RF, Geborek P, Forslind K, Albertsson K, Ernestam S, Petersson IF, et al. Conventional combination treatment versus biological treatment in methotrexate-refractory early rheumatoid arthritis: 2 Year follow-up of the randomised, non-blinded, parallel-group Swefot trial. Lancet 2012; 379:1712-20.

28. Sawalha AH, Zhao M, Coit P, Lu Q. Epigenetic dysregulation of ACE2 and interferon-regulated genes might suggest increased COVID-19 susceptibility and severity in lupus patients. Clin Immunol 2020; 215:108410.

29. Chiu Y-M, Chen D-Y. Infection risk in patients undergoing treatment for inflammatory arthritis: nonbiologics versus biologics. Expert Rev Clin Immunol 2020; 16:207-28

Table 1. Characteristics of the study population [N (\%)].

\begin{tabular}{|c|c|c|c|}
\hline Characteristic & All $(\mathrm{N}=2494)$ & Women $(\mathrm{N}=1592)$ & $\operatorname{Men}(\mathrm{N}=902)$ \\
\hline Age $[$ mean $(\mathrm{SD})]$ & $58.7(15.7)$ & $60.6(15.5)$ & $55.5(15.6)$ \\
\hline \multicolumn{4}{|l|}{$\begin{array}{l}\text { Primary inflammatory } \\
\text { disease diagnosis }\end{array}$} \\
\hline Spondylarthritis & $812(32.6 \%)$ & $359(22.6 \%)$ & $453(50.2 \%)$ \\
\hline Rheumatoid Arthritis & $538(21.6 \%)$ & $424(26.6 \%)$ & $114(12.6 \%)$ \\
\hline Osteoarthritis & $627(25.1 \%)$ & $480(30.2 \%)$ & $147(16.3 \%)$ \\
\hline $\begin{array}{l}\text { Systemic autoimmune } \\
\text { rheumatic diseases }\end{array}$ & $165(6.62 \%)$ & $149(9.36 \%)$ & $16(1.77 \%)$ \\
\hline Vasculitis & $59(2.37 \%)$ & $37(2.32 \%)$ & $22(2.44 \%)$ \\
\hline Other rheumatic diseases & $38(1.52 \%)$ & $26(1.63 \%)$ & $12(1.33 \%)$ \\
\hline Juvenile Arthritis & $7(0.28 \%)$ & $4(0.25 \%)$ & $3(0.33 \%)$ \\
\hline Dermatological diseases & $208(8.34 \%)$ & $82(5.15 \%)$ & $126(14.0 \%)$ \\
\hline Other & $40(1.60 \%)$ & $31(1.95 \%)$ & $9(1.00 \%)$ \\
\hline \multicolumn{4}{|l|}{ Coexisting conditions } \\
\hline Hypertension & $858(34.4 \%)$ & $553(34.7 \%)$ & $305(33.8 \%)$ \\
\hline Diabetes & $302(12.1 \%)$ & $174(10.9 \%)$ & $128(14.2 \%)$ \\
\hline Pulmonary disease & $364(14.6 \%)$ & $241(15.1 \%)$ & $123(13.6 \%)$ \\
\hline CV disease & $290(11.6 \%)$ & $179(11.2 \%)$ & $111(12.3 \%)$ \\
\hline Chronic kidney disease & $129(5.17 \%)$ & $76(4.77 \%)$ & $53(5.88 \%)$ \\
\hline $\begin{array}{l}\text { Cancer or active } \\
\text { treatment }\end{array}$ & $70(2.81 \%)$ & $47(2.95 \%)$ & $23(2.55 \%)$ \\
\hline $\begin{array}{l}\text { History of organ } \\
\text { transplantation }\end{array}$ & $8(0.32 \%)$ & $7(0.44 \%)$ & $1(0.11 \%)$ \\
\hline Any of these conditions & $1223(49.0 \%)$ & $797(50.1 \%)$ & $426(47.2 \%)$ \\
\hline
\end{tabular}




\begin{tabular}{|c|c|c|c|}
\hline Characteristic & All $(\mathrm{N}=\mathbf{2 4 9 4})$ & Women $(\mathrm{N}=1592)$ & $\operatorname{Men}(\mathrm{N}=902)$ \\
\hline \multicolumn{4}{|l|}{ Treatments followed } \\
\hline Biologic DMARDs ${ }^{1}$ & $1112(44.6 \%)$ & $579(36.4 \%)$ & $533(59.1 \%)$ \\
\hline Any $\mathrm{TNF} \alpha$ antagonist & $768(30.8 \%)$ & $388(24.4 \%)$ & $380(42.1 \%)$ \\
\hline Adalimumab & $367(14.7 \%)$ & $163(10.2 \%)$ & $204(22.6 \%)$ \\
\hline Etanercept & $183(7.34 \%)$ & $105(6.60 \%)$ & $78(8.65 \%)$ \\
\hline Infliximab & $120(4.81 \%)$ & $60(3.77 \%)$ & $60(6.65 \%)$ \\
\hline Golimumab & $65(2.61 \%)$ & $35(2.20 \%)$ & $30(3.33 \%)$ \\
\hline Certolizumab & $33(1.32 \%)$ & $25(1.57 \%)$ & $8(0.89 \%)$ \\
\hline Any pro-inflammatory & $279(11.2 \%)$ & $136(8.54 \%)$ & $143(15.9 \%)$ \\
\hline \multicolumn{4}{|l|}{ ILs antagonists } \\
\hline IL-6 antagonists & $52(2.09 \%)$ & $42(2.64 \%)$ & $10(1.11 \%)$ \\
\hline Tocilizumab & $46(1.84 \%)$ & $37(2.32 \%)$ & $9(1.00 \%)$ \\
\hline Sarilumab & $6(0.24 \%)$ & $5(0.31 \%)$ & $1(0.11 \%)$ \\
\hline IL-17 antagonists & $69(24.7 \%)$ & $26(19.1 \%)$ & $43(30.1 \%)$ \\
\hline Brodalumab & $2(0.72 \%)$ & $1(0.74 \%)$ & $1(0.70 \%)$ \\
\hline Secukinumab & $51(2.04 \%)$ & $22(1.38 \%)$ & $29(3.22 \%)$ \\
\hline Ixekizumab & $16(5.73 \%)$ & $3(2.21 \%)$ & $13(9.09 \%)$ \\
\hline IL-23(12) antagonists & $158(56.6 \%)$ & $68(50.0 \%)$ & $90(62.9 \%)$ \\
\hline Ustekinumab & $155(6.21 \%)$ & $67(4.21 \%)$ & $88(9.76 \%)$ \\
\hline Guselkumab & $3(1.08 \%)$ & $1(0.74 \%)$ & $2(1.40 \%)$ \\
\hline $\begin{array}{l}\text { Any } \mathrm{T} \text { lymphocyte } \\
\text { antagonist }\end{array}$ & $29(1.16 \%)$ & $22(1.38 \%)$ & $7(0.78 \%)$ \\
\hline $\begin{array}{l}\text { Any B lymphocyte } \\
\text { antagonist }\end{array}$ & $42(1.68 \%)$ & $36(2.26 \%)$ & $6(0.67 \%)$ \\
\hline Vedolizumab & $3(0.12 \%)$ & $2(0.13 \%)$ & $1(0.11 \%)$ \\
\hline Synthetic DMARDs ${ }^{2}$ & $850(34.1 \%)$ & $583(36.6 \%)$ & $267(29.6 \%)$ \\
\hline Methotrexate & $538(21.6 \%)$ & $366(23.0 \%)$ & $172(19.1 \%)$ \\
\hline Leflunomide & $116(4.65 \%)$ & $86(5.40 \%)$ & $30(3.33 \%)$ \\
\hline Chloroquine or & $115(4.61 \%)$ & $105(6.60 \%)$ & $10(1.11 \%)$ \\
\hline \multicolumn{4}{|l|}{ Hydroxychloroquine } \\
\hline Azathioprine & $80(3.21 \%)$ & $52(3.27 \%)$ & $28(3.10 \%)$ \\
\hline JAK inhibitors & $41(1.64 \%)$ & $32(2.01 \%)$ & $9(1.00 \%)$ \\
\hline Apremilast & $52(2.09 \%)$ & $20(1.26 \%)$ & $32(3.55 \%)$ \\
\hline Sulfasalazine & $10(0.40 \%)$ & $7(0.44 \%)$ & $3(0.33 \%)$ \\
\hline Mycophenolate & $19(0.76 \%)$ & $17(1.07 \%)$ & $2(0.22 \%)$ \\
\hline Tacrolimus & $24(0.96 \%)$ & $17(1.07 \%)$ & $7(0.78 \%)$ \\
\hline Cyclosporine & $3(0.12 \%)$ & $2(0.13 \%)$ & $1(0.11 \%)$ \\
\hline \multicolumn{4}{|l|}{ Dose of } \\
\hline \multicolumn{4}{|l|}{ Glucocorticoids: } \\
\hline [?]10 mg/d & $441(17.7 \%)$ & $347(21.8 \%)$ & $94(10.4 \%)$ \\
\hline$>10 \mathrm{mg} / \mathrm{d}$ & $86(3.45 \%)$ & $62(3.89 \%)$ & $24(2.66 \%)$ \\
\hline $\begin{array}{l}\text { Anti-hypertensive } \\
\text { drugs }^{3}\end{array}$ & $684(27.4 \%)$ & $428(26.9 \%)$ & $256(28.4 \%)$ \\
\hline ACE inhibitors & $397(15.9 \%)$ & $237(14.9 \%)$ & $160(17.7 \%)$ \\
\hline $\mathrm{ARBs}$ & $293(11.7 \%)$ & $194(12.2 \%)$ & $99(11.0 \%)$ \\
\hline Chronic NSAIDs & $498(20.0 \%)$ & $345(21.7 \%)$ & $153(17.0 \%)$ \\
\hline \multicolumn{4}{|l|}{ COVID-19 status } \\
\hline Confirmed or high & $156(6.26 \%)$ & $108(6.78 \%)$ & $48(5.32 \%)$ \\
\hline
\end{tabular}




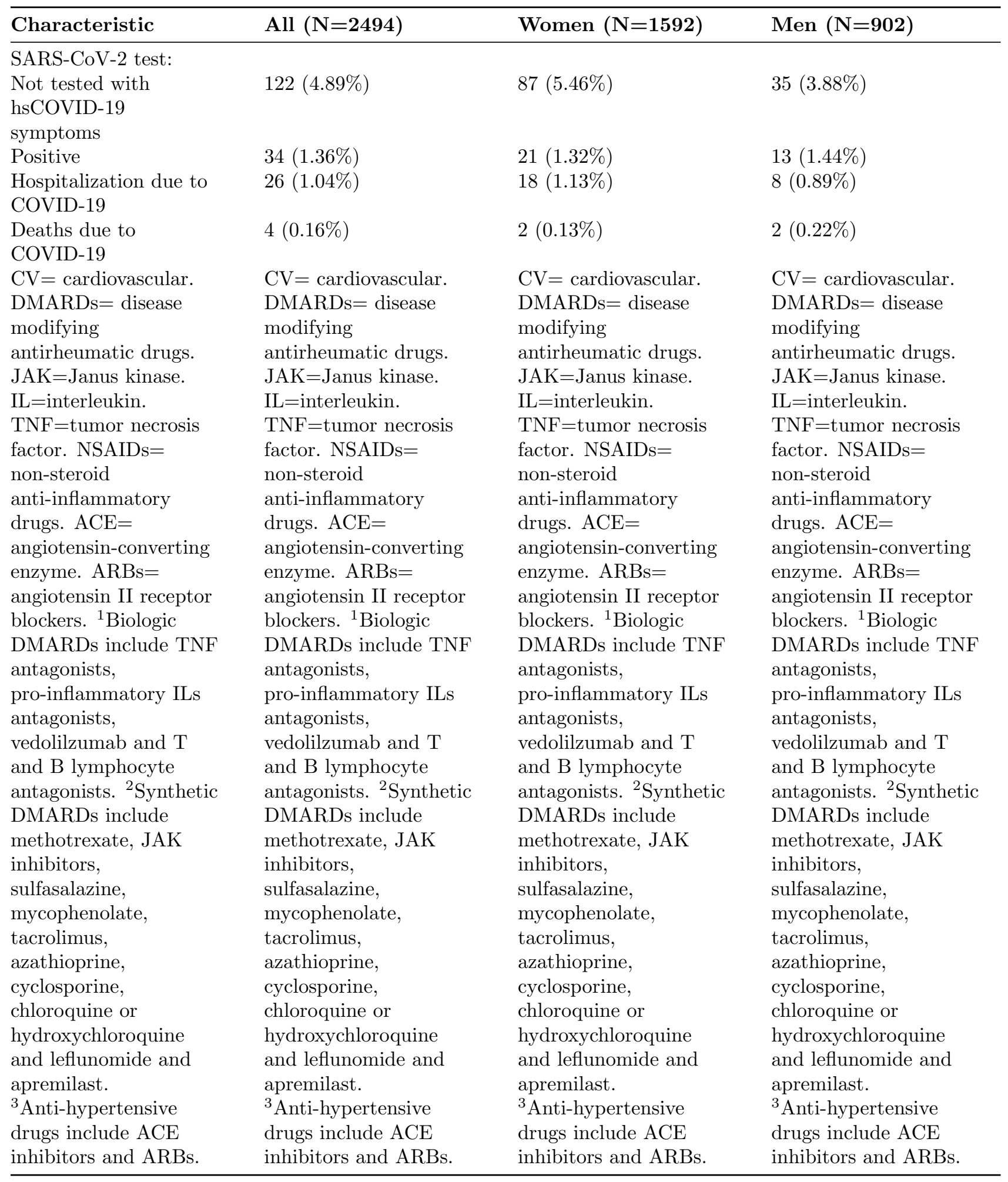

Table 2. Distribution of confirmed or high suspected COVID-19 symptoms across categories of study variables 


\begin{tabular}{|c|c|c|c|c|c|c|}
\hline & All & All & Women & Women & Men & Men \\
\hline & $\begin{array}{l}\text { No } \\
\text { Symptoms } \\
(\mathrm{N}=2338)\end{array}$ & $\begin{array}{l}\text { Symptoms } \\
(\mathrm{N}=156)\end{array}$ & $\begin{array}{l}\text { No } \\
\text { Symptoms } \\
(\mathrm{N}=1484)\end{array}$ & $\begin{array}{l}\text { Symptoms } \\
(\mathrm{N}=108)\end{array}$ & $\begin{array}{l}\text { No } \\
\text { Symptoms } \\
(\mathrm{N}=854)\end{array}$ & $\begin{array}{l}\text { Symptoms } \\
(\mathrm{N}=48)\end{array}$ \\
\hline $\begin{array}{l}\text { Age [mean } \\
\text { (SD)] }\end{array}$ & $58.5(15.7)$ & $62.1(16.2)$ & $60.3(15.5)$ & $64.8(15.5)$ & $55.5(15.5)$ & $56.0(16.1)$ \\
\hline $\begin{array}{l}\text { Primary } \\
\text { inflamma- } \\
\text { tory } \\
\text { disease } \\
\text { diagnosis }\end{array}$ & & & & & & \\
\hline Spondylarthritis & $770(32.9 \%)$ & $42(26.9 \%)$ & $340(22.9 \%)$ & $19(17.6 \%)$ & $430(50.4 \%)$ & $23(47.9 \%)$ \\
\hline $\begin{array}{l}\text { Rheumatoid } \\
\text { Arthritis }\end{array}$ & $519(22.2 \%)$ & $19(12.2 \%)$ & $408(27.5 \%)$ & $16(14.8 \%)$ & $111(13.0 \%)$ & $3(6.25 \%)$ \\
\hline Osteoarthritis & $563(24.1 \%)$ & $64(41.0 \%)$ & $424(28.6 \%)$ & $56(51.9 \%)$ & $139(16.3 \%)$ & $8(16.7 \%)$ \\
\hline $\begin{array}{l}\text { Systemic } \\
\text { autoimmune } \\
\text { rheumatic } \\
\text { diseases }\end{array}$ & $159(6.80 \%)$ & $6(3.85 \%)$ & $145(9.77 \%)$ & $4(3.70 \%)$ & $14(1.64 \%)$ & $2(4.17 \%)$ \\
\hline Vasculitis & $53(2.27 \%)$ & $6(3.85 \%)$ & $35(2.36 \%)$ & $2(1.85 \%)$ & $18(2.11 \%)$ & $4(8.33 \%)$ \\
\hline $\begin{array}{l}\text { Other } \\
\text { rheumatic } \\
\text { diseases }\end{array}$ & $26(11.1 \%)$ & $12(7.69 \%)$ & $22(1.48 \%)$ & $4(3.70 \%)$ & $9(1.05 \%)$ & $3(6.25 \%)$ \\
\hline $\begin{array}{l}\text { Juvenile } \\
\text { Arthritis }\end{array}$ & $7(0.30 \%)$ & $0(0.00 \%)$ & $4(0.27 \%)$ & $0(0.00 \%)$ & $3(0.35 \%)$ & $0(0.00 \%)$ \\
\hline $\begin{array}{l}\text { Dermatological } \\
\text { diseases }\end{array}$ & $202(8.64 \%)$ & $6(3.85 \%)$ & $80(5.39 \%)$ & $2(1.85 \%)$ & $122(14.3 \%)$ & $4(8.33 \%)$ \\
\hline $\begin{array}{l}\text { Other } \\
\text { Coexisting } \\
\text { conditions }\end{array}$ & $31(1.33 \%)$ & $9(5.77 \%)$ & $26(1.75 \%)$ & $5(4.63 \%)$ & $8(0.94 \%)$ & $1(2.08 \%)$ \\
\hline Hypertension & $788(33.7 \%)$ & $70(44.9 \%)$ & $505(34.0 \%)$ & $48(44.4 \%)$ & $283(33.1 \%)$ & $22(45.8 \%)$ \\
\hline Diabetes & $270(11.5 \%)$ & $32(20.5 \%)$ & $152(10.2 \%)$ & $22(20.4 \%)$ & $118(13.8 \%)$ & $10(20.8 \%)$ \\
\hline $\begin{array}{l}\text { Pulmonary } \\
\text { disease }\end{array}$ & $329(14.1 \%)$ & $35(22.4 \%)$ & $216(14.6 \%)$ & $25(23.1 \%)$ & $113(13.2 \%)$ & $10(20.8 \%)$ \\
\hline CV disease & $265(11.3 \%)$ & $25(16.0 \%)$ & $161(10.8 \%)$ & $18(16.7 \%)$ & $104(12.2 \%)$ & $7(14.6 \%)$ \\
\hline $\begin{array}{l}\text { Chronic } \\
\text { kidney disease }\end{array}$ & $117(5.00 \%)$ & $12(7.69 \%)$ & $70(4.72 \%)$ & $6(5.56 \%)$ & $47(5.50 \%)$ & $6(12.5 \%)$ \\
\hline $\begin{array}{l}\text { Cancer or } \\
\text { active } \\
\text { treatment }\end{array}$ & $64(2.74 \%)$ & $6(3.85 \%)$ & $43(2.90 \%)$ & $4(3.70 \%)$ & $21(2.46 \%)$ & $2(4.17 \%)$ \\
\hline $\begin{array}{l}\text { History of } \\
\text { organ } \\
\text { transplantation }\end{array}$ & $7(0.30 \%)$ & $1(0.64 \%)$ & $6(0.40 \%)$ & $1(0.93 \%)$ & $1(0.12 \%)$ & $0(0.00 \%)$ \\
\hline $\begin{array}{l}\text { Any of these } \\
\text { conditions } \\
\text { Treatments } \\
\text { followed }\end{array}$ & $1122(48.0 \%)$ & $101(64.7 \%)$ & $728(49.1 \%)$ & $69(63.9 \%)$ & $394(46.1 \%)$ & $32(66.7 \%)$ \\
\hline $\begin{array}{l}\text { Biologic } \\
\text { DMARDs }^{1}\end{array}$ & $\begin{array}{l}1070 \\
(45.8 \%)\end{array}$ & $42(26.9 \%)$ & $560(37.7 \%)$ & $19(17.6 \%)$ & $510(59.7 \%)$ & $23(47.9 \%)$ \\
\hline $\begin{array}{l}\text { Any } \mathrm{TNF} \alpha \\
\text { antagonist }\end{array}$ & $739(31.6 \%)$ & $29(18.6 \%)$ & $378(25.5 \%)$ & $10(9.26 \%)$ & $361(42.3 \%)$ & $19(39.6 \%)$ \\
\hline
\end{tabular}




\begin{tabular}{|c|c|c|c|c|c|c|}
\hline & All & All & Women & Women & Men & Men \\
\hline Adalimumab & $353(15.1 \%)$ & $14(8.97 \%)$ & $159(10.7 \%)$ & $4(3.70 \%)$ & $194(22.7 \%)$ & $10(20.8 \%)$ \\
\hline Etanercept & $178(7.61 \%)$ & $5(3.21 \%)$ & $104(7.01 \%)$ & $1(0.93 \%)$ & $74(8.67 \%)$ & $4(8.33 \%)$ \\
\hline Infliximab & $114(4.88 \%)$ & $6(3.85 \%)$ & $57(3.84 \%)$ & $3(2.78 \%)$ & $57(6.67 \%)$ & $3(6.25 \%)$ \\
\hline Golimumab & $63(2.69 \%)$ & $2(1.28 \%)$ & $34(2.29 \%)$ & $1(0.93 \%)$ & $29(3.40 \%)$ & $1(2.08 \%)$ \\
\hline Certolizumab & $31(1.33 \%)$ & $2(1.28 \%)$ & $24(1.62 \%)$ & $1(0.93 \%)$ & $7(0.82 \%)$ & $1(2.08 \%)$ \\
\hline All & $269(11.5 \%)$ & $10(6.41 \%)$ & $130(8.76 \%)$ & $6(5.56 \%)$ & $139(16.3 \%)$ & $4(8.33 \%)$ \\
\hline \multicolumn{7}{|l|}{$\begin{array}{l}\text { IL-6/12/17/23 } \\
\text { antagonists }\end{array}$} \\
\hline $\begin{array}{l}\text { IL-6 } \\
\text { antagonists }\end{array}$ & $52(2.22 \%)$ & $0(0.00 \%)$ & $42(2.83 \%)$ & $0(0.00 \%)$ & $10(1.17 \%)$ & $0(0.00 \%)$ \\
\hline $\begin{array}{l}\text { IL-17 } \\
\text { antagonists }\end{array}$ & $68(2.91 \%)$ & $1(0.64 \%)$ & $26(1.75 \%)$ & $0(0.00 \%)$ & $42(4.92 \%)$ & $1(2.08 \%)$ \\
\hline $\begin{array}{l}\text { IL- } 12 / 23 \\
\text { antagonists }\end{array}$ & $149(6.37 \%)$ & $9(5.77 \%)$ & $62(4.18 \%)$ & $6(5.56 \%)$ & $87(10.2 \%)$ & $3(6.25 \%)$ \\
\hline $\begin{array}{l}\mathrm{T} \text { lymphocyte } \\
\text { antagonists }\end{array}$ & $27(1.15 \%)$ & $2(1.28 \%)$ & $20(1.35 \%)$ & $2(1.85 \%)$ & $7(0.82 \%)$ & $0(0.00 \%)$ \\
\hline $\begin{array}{l}\text { B lymphocyte } \\
\text { antagonists }\end{array}$ & $42(1.80 \%)$ & $0(0.00 \%)$ & $36(2.43 \%)$ & $0(0.00 \%)$ & $6(0.70 \%)$ & $0(0.00 \%)$ \\
\hline Vedolizumab & $2(0.09 \%)$ & $1(0.64 \%)$ & $1(0.07 \%)$ & $1(0.93 \%)$ & $1(0.12 \%)$ & $0(0.00 \%)$ \\
\hline Synthetic & $807(34.5 \%)$ & $43(27.6 \%)$ & $553(37.3 \%)$ & $30(27.8 \%)$ & $254(29.7 \%)$ & $13(27.1 \%)$ \\
\hline \multicolumn{7}{|l|}{ DMARDs $^{2}$} \\
\hline Methotrexate & $510(21.8 \%)$ & $28(17.9 \%)$ & $348(23.5 \%)$ & $18(16.7 \%)$ & $162(19.0 \%)$ & $10(20.8 \%)$ \\
\hline Leflunomide & $111(4.75 \%)$ & $5(3.21 \%)$ & $82(5.53 \%)$ & $4(3.70 \%)$ & $29(3.40 \%)$ & $1(2.08 \%)$ \\
\hline Apremilast & $51(2.18 \%)$ & $1(0.64 \%)$ & $19(1.28 \%)$ & $1(0.93 \%)$ & $32(3.75 \%)$ & $0(0.00 \%)$ \\
\hline Chloroquine or & $108(4.62 \%)$ & $7(4.49 \%)$ & $99(6.67 \%)$ & $6(5.56 \%)$ & $9(1.05 \%)$ & $1(2.08 \%)$ \\
\hline \multicolumn{7}{|c|}{ Hydroxychloroquine } \\
\hline JAK inhibitors & $39(1.67 \%)$ & $2(1.28 \%)$ & $30(2.02 \%)$ & $2(1.85 \%)$ & $9(1.05 \%)$ & $0(0.00 \%)$ \\
\hline Sulfasalazine & $9(0.38 \%)$ & $1(0.64 \%)$ & $7(0.47 \%)$ & $0(0.00 \%)$ & $2(0.23 \%)$ & $1(2.08 \%)$ \\
\hline Mycophenolate & $18(0.77 \%)$ & $1(0.64 \%)$ & $16(1.08 \%)$ & $1(0.93 \%)$ & $2(0.23 \%)$ & $0(0.00 \%)$ \\
\hline Tacrolimus & $22(0.94 \%)$ & $2(1.28 \%)$ & $15(1.01 \%)$ & $2(1.85 \%)$ & $7(0.82 \%)$ & $0(0.00 \%)$ \\
\hline Azathioprine & $77(3.29 \%)$ & $3(1.92 \%)$ & $50(3.37 \%)$ & $2(1.85 \%)$ & $27(3.16 \%)$ & $1(2.08 \%)$ \\
\hline Cyclosporine & $3(0.13 \%)$ & $0(0.00 \%)$ & $2(0.13 \%)$ & $0(0.00 \%)$ & $1(0.12 \%)$ & $0(0.00 \%)$ \\
\hline \multicolumn{7}{|l|}{ Glucocorticoids } \\
\hline [?]10 mg/d & $415(17.8 \%)$ & $26(16.7 \%)$ & $330(22.2 \%)$ & $17(15.7 \%)$ & $85(9.95 \%)$ & $9(18.8 \%)$ \\
\hline$>10 \mathrm{mg} / \mathrm{d}$ & $77(3.29 \%)$ & $9(5.77 \%)$ & $55(3.71 \%)$ & $7(6.48 \%)$ & $22(2.58 \%)$ & $2(4.17 \%)$ \\
\hline $\begin{array}{l}\text { Anti- } \\
\text { hypertensive } \\
\text { drugs }^{3}\end{array}$ & $631(27.0 \%)$ & $53(34.0 \%)$ & $391(26.3 \%)$ & $37(34.3 \%)$ & $240(28.1 \%)$ & $16(33.3 \%)$ \\
\hline $\begin{array}{l}\mathrm{ACE} \\
\text { inhibitors }\end{array}$ & $375(16.0 \%)$ & $22(14.1 \%)$ & $221(14.9 \%)$ & $16(14.8 \%)$ & $154(18.0 \%)$ & $6(12.5 \%)$ \\
\hline ARBs & $260(11.1 \%)$ & $33(21.2 \%)$ & $172(11.6 \%)$ & $22(20.4 \%)$ & $88(10.3 \%)$ & $11(22.9 \%)$ \\
\hline Chronic & $461(19.7 \%)$ & $37(23.7 \%)$ & $320(21.6 \%)$ & $25(23.1 \%)$ & $141(16.5 \%)$ & $12(25.0 \%)$ \\
\hline
\end{tabular}




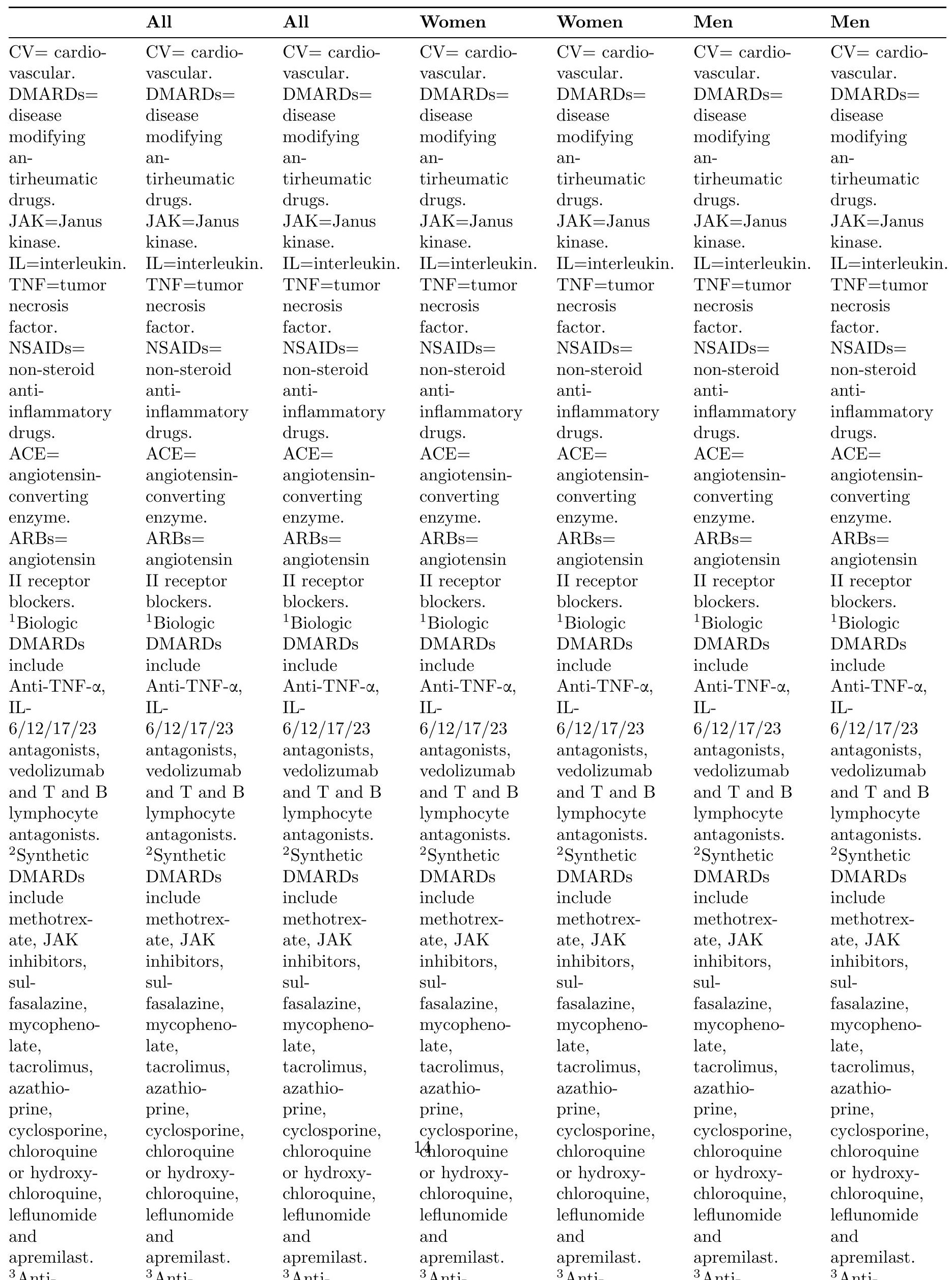




\begin{tabular}{llllll}
\hline All & All & Women & Women & Men & Men \\
\hline
\end{tabular}

Table 3. Adjusted Relative Risk* (aRR) with 95\% confidence intervals (CI95\%) of confirmed or high suspected COVID-19 symptoms according to the presence of several comorbidities and treatments, stratified by sex. 

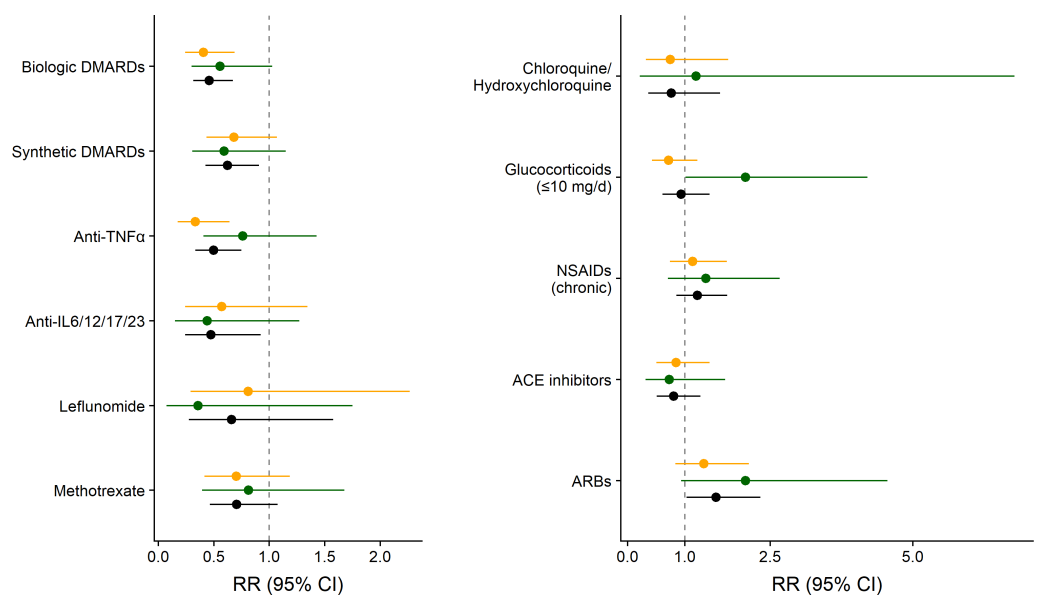

16 